\title{
Antral hypertrophic gastritis: a rare cause of iron deficiency
}

\author{
GWH STAMP, ${ }^{*}$ K PALMER, $\dagger J J$ MISIEWICZ† \\ From the Departments of Histopathology* and Gastroenterology, $†$ Central Middlesex Hospital, \\ London NW10
}

SUMMARY A case of an unusual hypertrophic gastropathy confined to the gastric antrum which? presented with chronic anaemia is described. The clinical and pathological features are contrasted $\omega_{0}$ with Menetrier's disease and hypersecretory hypertrophic gastropathy, and a possible relation to solitary hyperplastic (regenerative) polyps is discussed.

We report a case of chronic iron deficiency anaemia due to bleeding from a hypertrophic gastropathy affecting the whole of the gastric antral mucosa. Although chronic blood loss has been reported in association with Menetrier's disease, we believe that this case represents a quite separate entity.

\section{Case presentation}

A 72 year old white woman presented with symptoms of malaise and dizziness. Physical examination was normal apart from pallor. The haemoglobin concentration was $9.6 \mathrm{~g} / \mathrm{dl}$, reticulocyte count $2.2 \%$, mean corpuscular volume $80 \mathrm{fl}$, mean corpuscular haemoglobin concentration $28 \%$, and the blood film was consistent with iron deficiency. Faecal occult blood tests were strongly positive. Sigmoidoscopy, barium enema, and barium meal examinations were normal. Despite six months' oral iron supplements the haemoglobin concentration did not rise, and endoscopy showed a small hiatus hernia and friable, thickened antral mucosal folds. Histology of antral biopsies showed widening and lengthening of the superficial part of the pyloric glands, forming villus like structures. There was little inflammatory infiltrate in the lamina propria and no evidence of malignancy. Biopsies from the remainder of the stomach showed mild chronic gastritis with focal intestinal metaplasia.

During the next six years anaemia worsened and frequent blood transfusions were necessary, but albumin, vitamin $B_{12}$, and folate concentrations remained normal. Coeliac axis angiography, further barium meal and barium enema examinations, and colonoscopy were unremarkable. Repeated upper $\frac{7}{0}$ gastrointestinal endoscopic and histopathological examinations were unchanged.

In view of debilitating symptoms of anaemia and increasing transfusion requirements, a Polya partial gastrectomy was performed 10 years after initial presentation. At laparotomy the gastric antral mucosa was obviously thickened but no other

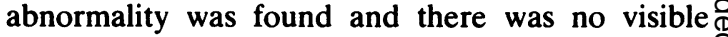
alternative bleeding site. Six months after surgery anaemia had not returned.

\section{PATHOLOGICAL EXAMINATION}

In the resected stomach the antrum had a coarsely thickened, cobblestone appearance with a boggy용 texture (Fig. 1). There were pseudo-polypoid long- 0 itudinal ridges up to $2.4 \mathrm{~cm}$ in depth. The proximal 3 . gastric mucosa appeared atrophic. No ulcers were? seen.

Microscopical examination of the antral mucosa showed villiform hyperplasia of the surface glandular epithelium with elongation of the gastric pits, some of which were thrown into complex folds, with focal dilatation of the glands (Fig. 2). The epithelium was predominantly composed of neutral $N$ mucin-containing surface gastric cells interspersed with a few goblet cells containing acid mucin. The lamina propria was oedematous, inflammatory cells were scanty, and vertically orientated smooth mus- $\frac{\bar{D}}{\bar{D}}$ cle cells and fibroblasts extended inwards from the muscularis mucosae. Prominent microthrombi were 0 noted in the superficial capillary vessels (Fig. 3) and the submucosal vessels were congested, but there $\vec{\Phi}$ were no features to suggest any underlying vascular $\overrightarrow{\mathbb{D}}$ hamartoma or angiodysplasia. The deeper pyloric $\frac{\varrho}{\sigma}$ glands were relatively unaffected and there was no 


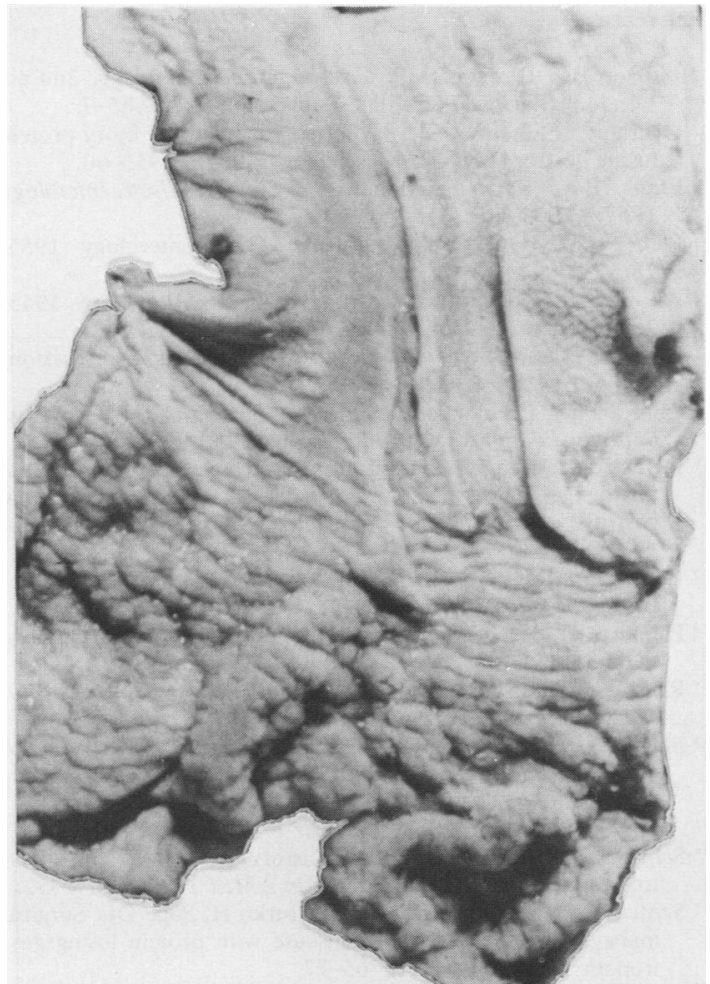

Fig. 1 Irregular generalised thickening of the antrum with pseudo-polypoidal longitudinal ridges. The proximal mucosa is featureless.

excess of argyrophilic cells. The overall architecture resembled a hyperplastic polyp, but multiple sections established that the changes affected the whole of the antral mucosa. The proximal stomach showed mild active chronic gastritis affecting body type mucosa, with extensive intestinal metaplasia.

\section{Discussion}

Antral mucosal hypertrophy is exceedingly rare: most reported cases occur with involvement of the whole stomach..$^{1-4}$ Localised antral hypertrophic gastritis has not previously been well documented by biopsy. ${ }^{5-7}$ Although it is possible that in our case an initial generalised hypertrophic gastritis partially regressed leaving the abnormal antral region, ${ }^{389}$ the long period of observation makes this unlikely.

The clinical presentation, distribution, and histological pattern are not those of classical Menetrier's disease, which characteristically affects the body of the stomach and spares the antrum. ${ }^{1011}$ Anaemia is unusual in Menetrier's disease. ${ }^{12}$ Blood

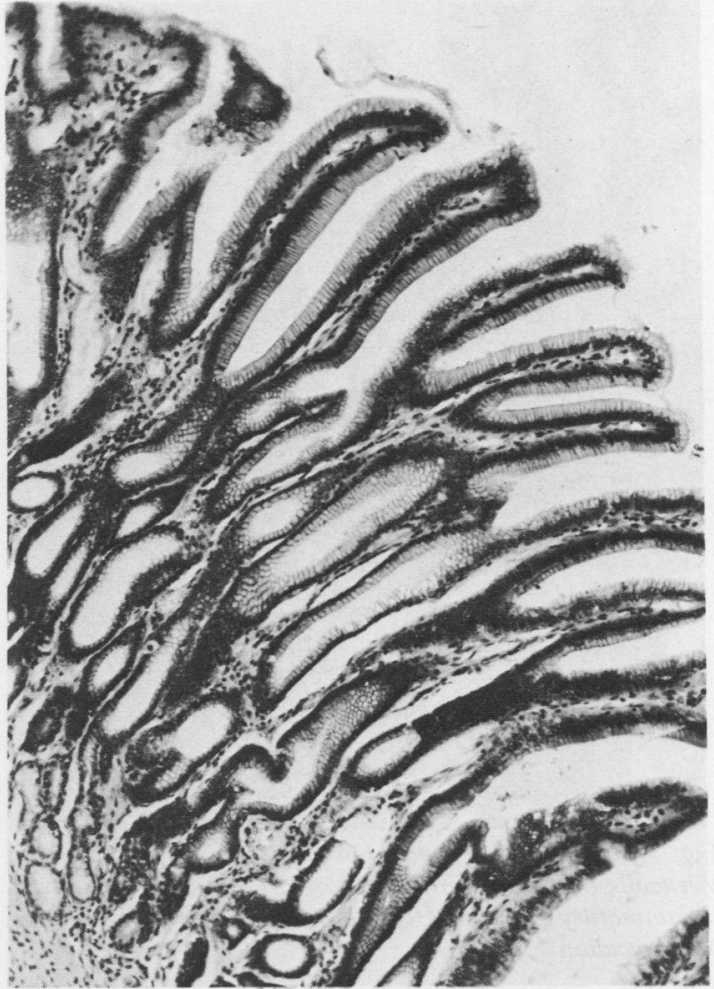

Fig. 2 Pronounced villiform hyperplasia of the surface epithelium with elongation of the pits. Haematoxylin and eosin. Original magnification $\times 115$.

loss in our patient probably resulted from trauma to the dilated superficial mucosal capillary vessels, possibly exacerbated by microthrombus formation leading to ischaemic damage. The protein losing enteropathy which commonly occurs in Menetrier's disease $^{13-16}$ was not present in our case. Finally, Menetrier's disease is characterised by hyperplasia of the surface mucus secreting epithelium and foveolae, extending into the pits leading to corkscrew dilatation of the glands, ${ }^{13}$ rather than the relatively superficial hyperplasia seen in our case.

Hypertrophic hypersecretory gastropathy, a variant of Menetrier's disease, is characterised by a considerably increased parietal cell mass and acid hypersecretion. ${ }^{17}{ }^{18}$ Histologically, all glandular elements are involved ${ }^{17}$ and the disease affects the whole stomach. In our case the mucosa of the gastric body was atrophic, and, although acid secretion studies were not performed, we believe it unlikely that our case represents this disease entity.

The histology of the antrum in this patient resembled that of isolated hypertrophic (regenerative) polyps, originally also described by Menetrier. ${ }^{10}$ 


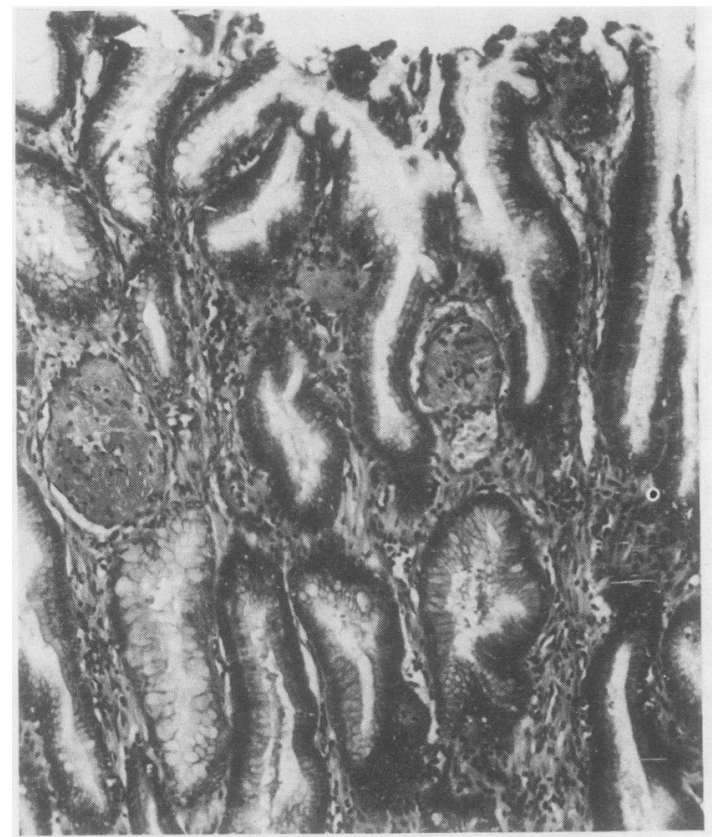

Fig. 3 Capillary microthrombi in the lamina propria. Vertically orientated fibroblasts are present, with a scanty inflammatory infiltrate. Haematoxylin and eosin. Original magnification $\times 280$.

These are normally found at the junction of the body and the antrum. ${ }^{19}$ It is conceivable that this was a diffuse form of this disease, although this has not previously been described.

We are most grateful to Dr AB Price, Department of Histopathology, Northwick Park Hospital; Professor D Allison and Professor NA Wright, Departments of Radiodiagnosis and Histopathology, Hammersmith Hospital, for their advice; and to Miss TJ Murphy, Department of Histopathology, Central Middlesex Hospital for technical assistance.

\section{References}

${ }^{1}$ Morson BC, Dawson IMP. Gastrointestinal pathology. 2nd ed. London: Blackwell Scientific Publications, 1979:85-7.

2 Overholt BF, Jeffries GH. Hypertrophic hypersecretory protein losing gastropathy. Gastroenterology 1967;53:953-60.

${ }^{3}$ Frank BW, Kern F. Menetrier's disease. Gastroenterology 1967;53:953-60.

${ }^{4}$ Fieber SS. Hypertrophic gastritis. Gastroenterology 1955; 28:39-67.

${ }^{5}$ Arendt J. Hypertrophic antrum gastritis. Ann Surg 1945; 2:235-52.

6 Hart D. Massive hypertrophic gastritis (quoted in discussion) Ann Surg 1952;5:653.

${ }^{7}$ Palmer PES. Giant hypertrophic (tumour-simulating) gastritis. Journal of the Faculty of Radiologists 1958;9:175-82.

8 Jarnum S, Jensen BJ. Plasma protein turnover (albumin, transferrin, IgG, IgM) in Menetrier's disease. (giant hypertrophic gastritis): evidence of non-selective protein loss. Gut $\infty$ 1972; 13:128-31.

'Berenson MM, Sannella J, Freston JW. Menetrier's disease. Gastroenterology 1976; 70:257-63.

${ }^{10}$ Palmer ED. What Menetrier really said. Gastrointest Endosc 1968; 15:83-90.

11 Russell IJ, Smith J, Dozois RR, Wahner HW, Bartholomew LG. Menetrier's disease. Mayo Clin Proc 1977;52:91-6.

12 Singh AK, Cumaraswamy RC, Corrin B. Diffuse hypertrophy of gastric mucosa (Menetrier's disease) and iron deficiency anaemia. Gut 1969;10:735-7.

${ }^{13}$ Anonymous. Menetrier's disease. Br Med J 1979;i:150.

${ }^{14}$ Scharschmidt BF. The natural history of hypertrophic gastropathy (Menetrier's disease). Am J Med 1977;63:644-52.

is Scott HW, Harrison HJ, Law DH, Burko H, Page DL. Surgical management of Menetrier's disease with protein losing gastropathy. Ann Surg 1975;765-77.

${ }^{16}$ Kelly DG, Miller LJ, Malagelada J-R, Huizenga KA, Markowitz H. Giant hypertrophic gastropathy (Menetrier's disease): pharmacological effects on protein leakage and mucosal ultrastructure. Gastroenterology 1982;83:581-9.

${ }^{17}$ Stempien SJ, Dagradi AE, Reingold IM, et al. Hypertrophic hypersecretory gastropathy. Am J Dig Dis 1964;9:471-93.

${ }^{18}$ Brooks AM, Isenberg J, Goldstein H. Giant thickening of the gastric mucosa with acid hypersecretion and protein losing gastropathy. Gastroenterology 1970;58:73-9.

14 Morson BC, Dawson IMP. Gastrointestinal pathology. 2nd ed. London: Blackwell Scientific Publications, 1979:140-7.

Requests for reprints to: Dr GWH Stamp. Department of Histopathology, Central Middlesex Hospital, Acton Lane, 을 London NW10 7NS, England. 